\title{
Genetic Structure of Populations of the Rice-Infecting Pathogen Rhizoctonia solani AG-1 IA from China
}

\author{
Joana Bernardes-de-Assis, Michelangelo Storari, Marcello Zala, Wenxiang Wang, Daohong Jiang, \\ Li ShiDong, Meisong Jin, Bruce A. McDonald, and Paulo C. Ceresini
}

First, second, third, eighth, and ninth authors: Plant Pathology, Institute of Integrative Biology, ETH Zurich, Universitaetstr. 2, LFW B28, 8092, Zurich, Switzerland; fourth author: Plant Protection Institute, Anhui Academy of Agricultural Science, Hefei, 230031, Anhui, China; fifth author: College of Plant Science and Technology, Huazhong Agricultural University, Wuhan, 430070, Hubei, China; sixth author: Soilborne Diseases Laboratory, State key Laboratory for Biology of Plant Diseases and Insect Pests, Institute of Plant Protection, The Chinese Academy of Agricultural Sciences, Beijing 100081, China; seventh author: Plant Protection Institute, Agricultural Academy of Zhejiang, Hangzhou, Zhejiang, China; and ninth author: UNESP, Campus de Ilha Solteira, Depto. de Fitossanidade, Engenharia Rural e Solos, 15385-000, Ilha Solteira, São Paulo, Brazil.

Accepted for publication 27 March 2009.

\begin{abstract}
Bernardes-de-Assis, J., Storari, M., Zala, J., Wang, W., Jiang, W., ShiDong, L., Jin, M., McDonald, B. A., and Ceresini, P. C. 2009. Genetic structure of populations of the rice-infecting pathogen Rhizoctonia solani AG-1 IA from China. Phytopathology 99:1090-1099.

Sheath blight disease (SBD) on rice, caused by Rhizoctonia solani AG1 IA, is one of the most devastating rice diseases on a global basis, including China (in Eastern Asia), the world's largest rice-growing country. We analyzed the population genetics of nine rice-infecting populations from China using nine microsatellite loci. One allopatric population from India (Southern Asia) was included in the analyses. In total, 300 different multilocus genotypes were found among 572 fungal isolates. Clonal fractions within rice fields were 16 to $95 \%$, suggesting that sclerotia were a major source of primary inoculum in some fields.

relatively high level of differentiation among populations overall; however, pairwise comparisons gave nonsignificant $\mathrm{R}_{\mathrm{ST}}$ values, consistent with contemporary gene flow among five of the populations. Four of these populations were located along the Yangtze River tributary network. Gene flow followed an isolation-by-distance model consistent with restricted long-distance migration. Historical migration rates were reconstructed and yielded values that explained the current levels of population subdivision. Except for one population which appeared to be strictly clonal, all populations showed evidence of a mixed reproductive mode, including both asexual and sexual reproduction. One population had a strictly recombining structure (all loci were in Hardy-Weinberg equilibrium) but the remaining populations from China and the one from India exhibited varying degrees of sexual reproduction. Six populations showed significant $\mathrm{F}_{\mathrm{IS}}$ values consistent with inbreeding.
\end{abstract} Global $\Phi_{\mathrm{ST}}$ statistics $\left(\Phi_{\mathrm{ST}}=42.49 ; P \leq 0.001\right)$ were consistent with a
The soilborne Basidiomycete fungus Rhizoctonia solani (teleomorph: Thanatephorus cucumeris) is a large species complex containing related but genetically distinct groups of pathogens affecting many plants species worldwide (11). Within the species complex, classification has been based on hyphal anastomosis grouping (8). Each anastomosis group (AG) is considered an independent evolutionary entity or phylospecies (11). The subgroup AG-1 IA is one of the most important plant pathogens worldwide, causing foliar diseases on maize, rice, and soybean (23). This study focuses on the rice sheath blight disease (SBD) in China, Eastern Asia, which is the world's largest rice-producing country. The first description of rice sheath blight is from Japan at the beginning of the twentieth century. The disease has been subsequently reported from most rice-growing areas of the world $(23,25,37)$. SBD on rice is considered to be one of the most devastating diseases on a global scale. In China, particularly, SBD

Corresponding author: P. C. Ceresini; E-mail address: paulo.ceresini@agrl.ethz.ch

* The $\boldsymbol{e}$-Xtra logo stands for "electronic extra" and indicates that the online version contains five supplemental files showing the geographical origin of the populations, the allele frequency distributions and information content associated with the nine microsatellite loci, the membership coefficient of multilocus genotypes to distinct populations, and the population sizes and historical migration rate estimates. Figure 2 appears in color online.

doi:10.1094/PHYTO-99-9-1090

(C) 2009 The American Phytopathological Society affects $\approx 15$ to 20 million ha of paddy-irrigated rice and causes a yield loss of $\approx 6$ million tons of rice grains per year (representing 3.14 to $3.51 \%$ average yield loss) $(40,43)$. However, yield losses per growing season could reach up to $50 \%$ (24). Highly resistant rice cultivars have not been found, but quantitative resistance exists (28). Until now, control strategies have relied mainly on fungicides but this option is not sustainable because of residue problems and potential risk of emergence of pathogen populations that are resistant to fungicides (54).

Rice SBD epidemics gradually decrease from southern to northern China, following the cline distribution of paddy rice cropping, which is most concentrated in the southeastern region (12). For instance, in the Yangtze River valley (in the centraleast), two epidemic peaks usually occur: one between June and July (during the Chinese Mei-Yu raining season) and one in September, when late-season rice milk stage coincides with diseaseconducive high temperature and moisture conditions (52). In northern China, where temperatures are lower and rainfall is scarcer than in the southeastern region, disease incidence is lower and only one epidemic peak usually occurs between May and September (52).

Despite the high yield losses caused by $R$. solani AG-1 IA on rice crops throughout the world, the population biology of the fungus is poorly understood. Information about the genetic structure of populations of $R$. solani AG-1 IA, its reproductive mode, and the patterns of migration in natural populations of the pathogen has just started to accumulate $(6,9,10,25,45)$. Knowledge 
about the population genetic structure of a pathogen provides insights into the evolutionary processes that have shaped populations and also can elucidate the evolutionary potential of populations subjected to different control strategies such as pesticide applications, resistance gene deployment, and cultural practices $(32,33,51)$. The main objective of this study was to determine the effects of recombination and gene flow (both current and historical) on Chinese populations of the rice-infecting pathogen $R$. solani AG-1 IA in agroecosystems from the center of origin of its host in Eastern Asia.

$R$. solani AG-1 IA was thought to be mainly an asexual fungus on rice, though sexual structures from its teleomorph ( $T$. $\mathrm{cu}$ cumeris) have been observed in rice fields (23). Classical population genetics studies using restriction fragment length polymorphism (RFLP) markers challenged this asexual view for riceinfecting $R$. solani AG-1 IA populations in Texas (45) and India (25). These studies pointed out a scenario in which, in addition to clonal propagation, the fungus also undergoes sexual recombination cycles that produce novel genotypes. The occurrence of a mixed reproductive mode was also postulated for rice- and soybean-infecting populations from Texas and Louisiana (United States) based on microsatellite genotyping (6).

The extent and range of gene flow mediated by sexual and asexual fungal propagules (such as basidiospores and sclerotia) determines the degree of population differentiation and the potential for genotype flow (32). Gene flow is influenced by geography, either through a process of isolation by distance or through the existence of connectivity or barriers to dispersal (21). The riceinfecting populations from Texas and India showed low levels of population subdivision, consistent with high levels of gene flow between these populations $(25,45)$. However, soybean-infecting populations from Brazil exhibited limited dispersal between geographically distant regions, supporting the hypothesis of restricted gene flow caused by geographic isolation (10).

By analyzing the distribution of genetic diversity within and among pathogen populations, it is also possible to determine historical patterns of migration and identify centers of diversity (5). Chinese populations of rice-infecting $R$. solani AG-1 IA were needed to unravel the genetic structure of the pathogen at the center of origin of its Poaceous host (Oryza sativa) (4) in Eastern Asia, which we postulated could also be a center of diversity and possible center of origin for $R$. solani AG-1 IA (45). We addressed the following questions in our analysis. (i) Are the rice-infecting populations of $R$. solani AG-1 IA from China genetically subdivided or does gene flow occur among these geographical populations? The Chinese rice-infecting populations of $R$. solani AG-1 IA were compared with an allopatric population from India (Southern Asia) to test the hypotheses of no genetic differentiation between sympatric and allopatric rice-infecting populations. (ii) Is the observed population subdivision consistent with an isolation-by-distance model? (iii) What are the historical and contemporary patterns of gene flow among geographical populations of $R$. solani AG-1 IA from China? (iv) Are these populations clonal or panmictic? Our null hypothesis was that geographical populations of $R$. solani AG-1 IA from China would be genetically homogenous (hence, nonsubdivided) and sexually recombining.

\section{MATERIALS AND METHODS}

Field sampling, fungal isolation, and DNA extraction from R. solani AG-1 IA. In total, 521 isolates were obtained in summer 2005 from nine naturally infected rice fields from seven different provinces representing the most important rice-producing areas in northern China (Beijing $[\mathrm{BJ}]$ ); the central-eastern or Yangtze River tributary region (Anhui [QI, WW, and TC], Zhejiang [ZU], and Hubei [WU] provinces); and southern China (GuangXi [GX], JiangXi [JX], and Hunan [HN] provinces). A map showing samp- ling locations is available as a supplementary file (e-Xtra). Geographical distances between fields ranged from $60 \mathrm{~km}$ (between TC and QI, from Qiasan County, Anhui) to $1,680 \mathrm{~km}$ (between BJ and GX [from Xinan County, Guangxi]).

Plants showing typical symptoms of rice SBD were collected using transect sampling from nine fields. Rice plants were sampled at the milk growth stage. From each field ( 0.5 to 0.6 ha), infected samples from six to eight disease foci separated by at least $10 \mathrm{~m}$ were collected along each transect from a total of seven to nine transects per field (totaling 42 to 72 foci per field). In total, 40 to 77 isolates were obtained from each field population. Isolations were made by transferring fragments of infected leaves to petri plates containing water agar (WA) medium and incubating at $25^{\circ} \mathrm{C}$ in the dark. After a 24 - to 48 -h incubation, hyphal tips from typical $R$. solani mycelia were transferred to potato dextrose agar (PDA). Five-day-old fungal cultures on PDA produced sasakii-type dark-walled sclerotia, typical of AG-1 IA $(30,48)$. Sclerotia produced by each isolate were transferred into 1.8-ml cryotubes (Nunc CryoLine System, Denmark) containing sterilized silica gel (Fluka Chemie GmbH, Germany) for longterm storage at $4^{\circ} \mathrm{C}$. DNA was extracted as described earlier (25). The AG of the isolates was determined by selective amplification of part of the 28S ribosomal DNA (rDNA) region of the fungus using the specific primers designed for $R$. solani AG-1 IA: $R$. solani AG-common primer (forward) 5'-CTCAAACAGGCATGCTC-3' and $R$. solani AG 1-IA specific primer (reverse) $5^{\prime}-$ CAGCAATAGTTGGTGGA-3' (29).

One rice-infecting population from India (Southern Asia) composed of 51 isolates obtained from a single rice field in northern Kerala (Pattambi) was included in our analysis as an allopatric population (i.e., occurring in a separate, nonoverlapping geographic area, probably unable to crossbreed because of geographic separation) for testing the hypothesis on isolation by distance. Details regarding the sampling strategy, isolation of the infected material, and DNA extraction methods for those isolates from India are given elsewhere (25). Geographical distances between the rice-infecting populations from China and India ranged from 3,980 km (between GX and Pattambi) to 5,100 km (between BJ and Pattambi).

Microsatellite genotyping. Each isolate from the 10 riceinfecting populations of $R$. solani AG-1 IA was genotyped using a specific set of nine polymorphic co-dominant microsatellite (SSR) loci (56) labeled with fluorescent primers. Polymerase chain reaction (PCR) amplifications were performed in 96-well plates in a total volume of $20 \mu \mathrm{l}$ with $5 \mu \mathrm{l}$ of genomic DNA (5 to $15 \mathrm{ng}$ of final concentration), $2 \mu \mathrm{l}$ of $10 \times$ reaction buffer $(100 \mathrm{mM}$ $\mathrm{KCl}, 100 \mathrm{mM}\left(\mathrm{NH}_{4}\right)_{2} \mathrm{SO}_{4}, 200 \mathrm{mM}$ Tris- $\mathrm{HCl}, 20 \mathrm{mM} \mathrm{MgCl}$, $0.1 \%$ Triton $\mathrm{X}-100, \mathrm{pH} 8.8$ ) (New England Biolabs, MA), $0.3 \mu \mathrm{M}$ each labeled (Applied Biosystems, CA) and nonlabeled primer (Microsynth, Balgach, Switzerland), $0.1 \mathrm{mM}$ each dNTP, and $0.5 \mathrm{U}$ of Taq polymerase (New England Biolabs). PCR amplifications included a 2.5 -min initial denaturation step at $96^{\circ} \mathrm{C}$; followed by 35 cycles of $30 \mathrm{~s}$ each at 96,50 , and $72^{\circ} \mathrm{C}$; and then a 5 -min final extension step at $72^{\circ} \mathrm{C}$. All amplification reactions were carried out in a Biometra T-gradient thermocycler (Biometra, Goettingen, Germany).

The fluorescent labeled PCR products were electrophoresed in an ABI PRISM3100 (Applied Biosystems) automated sequencer along with a fluorescently labeled size standard (GeneScan-500; Applied Biosystems). Labeling with four separate dyes enabled us to run at least five loci per well into two distinct sets (set 1: TC01, TC02, TC03, and TC05; set 2: TC06, TC07, TC10, TC12, and TC17). Locus TC17 is identical to TC13 from Zala et al. (56), except that it was labeled with PET instead of NED. Genescan and Genotyper version 3.7 software (Applied Biosystems) were used to score the size of PCR products. Two control isolates (TC05USA_KAT_C6 from soybean and TC05VNZ_A1A1 from rice) with SSR alleles of known sizes were included in every run 
of 94 samples. Reproducibility of the molecular markers was tested by contrasting sizes of each allele at every locus for 17 isolates (TC05CHN_BEJ_I_12, TC05CHN_BEJ_I_21, TC05CHN_BEJ_I_23, TC05CHN_BEJ_II_12, TC05CHN_BEJ_II_21 [from BJ], TC05CHN_GX01, TC05CHN_GX11, TC05CHN_GX16 [from GX], TC05CHN_HB10, TC05CHN_HB27, TC05CHN_HB04, TC05CHN_HB58 [from WU], TC07CHN_C1M, TC07CHN_F8M [from QI], TC07CHN_TA07, TC07CHN_TC10, and TC07CHN_TD4U [from WW]), randomly selected from the populations, which were independently genotyped twice. The statistical binning of the alleles into fragment size categories consistent with the repeat unit increments described by Zala et. al. (56) was implemented using the program FLEXIBIN (2). Considering the observed repeat units increments for our microsatellite loci from this and from three other studies $(6,10,17)$, we assumed a stepwise mutation model (SMM) in all the analyses.

Genetic data analysis: microsatellite information content. In all analyses, we assumed that $R$. solani AG-1 IA is a functional diploid (i.e., it is a dikaryon). All of our data were consistent with this assumption. Data on the range of repeats for each locus, number of alleles per locus, identification of private alleles, and allelic frequencies were assessed using the program CONVERT version 1.31 (16). The allele frequency distributions for the nine microsatellite loci are available in a supplementary file ( $e$-Xtra).

Genotype diversity. The multilocus microsatellite genotype (MLMG) for each strain was determined using the program GenoDive 2.0b7 (36). Isolates with the same MLMG were treated as clones. Several indices of clonal diversity were calculated for every population, including (i) the number of different multilocus genotypes; (ii) the clonal fraction (the proportion of fungal isolates originating from asexual reproduction), calculated as 1 [(number of different genotypes)/(total number of isolates)] (57); (iii) both the Stoddart and Taylor's genotypic diversity, $G_{o}=$ $1 / \Sigma p_{i}^{2}$, where $p_{i}$ is the frequency of the $i$ th genotype (50) and its evenness $\left(G_{o}\right.$ scaled by the maximum number of expected genotypes), an indicator for how evenly the genotypes are distributed over the population. To test whether pairs of populations differed in their clonal diversity indices, we performed a pairwise bootstrap test, where the individuals were resampled from the populations and the diversity indices were compared after every replicate (26) using 1,000 permutations with subsampling to match the size of the smallest population (19). The same program was used to perform clone correction, in which only one individual of each MLMG was included per population. All subsequent analyses were performed using clone-corrected field populations.

Gene diversity and differentiation among geographical populations. Gene diversity was quantified based on allelic richness and expected heterozygosity using the program FSTAT 2.9 .3 (18). Allelic richness was calculated according to El Mousadik and Petit (13) as the mean number of alleles per locus. Expected heterozygosity, or Nei's unbiased gene diversity (corrected for sample size), was calculated according to Nei (39) as $n /(n-1) \times\left(1-\Sigma_{i} p_{i}^{2}\right)$, where $p$ is the observed frequency of the $i$ th allele and $n$ is the sample size. To test whether populations differed for allelic richness and Nei's gene diversity, a bootstrapping approach based on 1,000 permutations was performed, also using the program FSTAT 2.9.3 (18).

Distribution of genetic variation was assessed by pairwise comparisons of populations using analysis of molecular variance (AMOVA) with the program ARLEQUIN 3.11 (14). The sum of squared size differences $\left(\Phi_{\mathrm{ST}}\right)$ between two haplotypes was used as the distance measure (47) assuming an SMM (3). Significance was assessed using 1,000 permutations. We also tested whether population subdivision followed the isolation-by-distance model proposed by Mantel (27). Mantel's test was carried out using GenoDive 2.0b7 (36) assuming a linear relationship between pair- wise values of $\mathrm{F}_{\mathrm{ST}}$ or $\Phi_{\mathrm{ST}} /(\mathrm{D} / 1-\mathrm{D})$ (where $\mathrm{D}$ is either $\mathrm{F}_{\mathrm{ST}}$ or $\Phi_{\mathrm{ST}}$ ) and the natural logarithm of geographic distances (kilometers) between all population pairs (46). The significance of the relationship was accessed with 1,000 permutations.

Reproductive mode. A test for Hardy Weinberg equilibrium (HWE) was performed for each locus with the program Arlequin 3.11 (14). This test is analogous to Fisher's exact test on a twoby-two contingency table but extended to a contingency table of arbitrary size $(20,42)$. $P$ values were obtained using a Markov Chain Monte Carlo (MCMC) approach, generating an exact probability distribution not biased by rare alleles (42).

Gametic equilibrium (GE) was tested using a multilocus association test (7). The hypothesis that genotypes at one locus are independent from genotypes at another locus was tested using an MCMC algorithm implemented in the program GenePop (42) available at http://genepop.curtin.edu.au/. We also measured the multilocus index of association $\left(I_{A}\right)$ (31) using the program Multilocus v1.3 (1). We tested the hypothesis of complete panmixia by comparing the observed data set to data sets in which an infinite amount of sexual recombination has been imposed on the data by randomly shuffling the alleles among individuals, independently for each locus. An $I_{A}$ significantly different from zero means disequilibrium.

Inbreeding, a possible cause of deviation from HWE and GE, was quantified based on values of $F_{I S}$ (the inbreeding coefficient) (55) calculated using Arlequin 3.11 (14) with 1,023 permutations of the data set.

Test for admixture or hidden population structure. Population admixture could be one of the causes of observed departures from HWE and GE. To determine whether any individuals in a sample were immigrants with respect to their reference geographical population, we used an assignment test performed with a Bayesian statistical model (41) implemented by STRUCTURE 2.2 (41). This program calculates the membership coefficients $(\hat{Q})$ of every MLMG to each of the populations. The MLMGs are assigned a priori to their reference population. By including this prior information, genotypes in the sample are assigned probabilistically to their reference population, or jointly to two or more populations if their genotypes are consistent with admixture. We performed 10 runs of MCMC simulations, with an initial burn-in of 10,000 followed by 100,000 iterations. Parameters were set using nine clusters $(K=9)$, admixture model, and $\mathrm{F}_{\mathrm{ST}}$ values previously calculated with ARLEQUIN 3.2 (14).

Historical migration. Theta values $(\theta)$ and the historical migration rates $(4 \mathrm{Nm})$ between rice-infecting populations were inferred using a maximum likelihood test based on an MCMC method implemented in MIGRATE 2.3 (5). MIGRATE is based on the coalescent theory and uses a maximum likelihood approach to estimate effective population sizes and a migration matrix (5). It allows for estimation of asymmetrical gene flow between population pairs. Values of $\theta$ represent a measure of effective population size (for diploids, $\theta=4 \mathrm{Ne} \mu$, where $\mathrm{Ne}=$ effective population size and $\mu=$ mutation rate inferred for each locus). The migration rate per generation is expressed as $4 \mathrm{Nm}$, which is just $\theta M(M=m / \mu$, where $m=$ immigration rate, a measure of how much more important immigration is over mutation to bring new variants into the population) (5). The data type chosen for the analysis was microsatellite data with Brownian motion, assuming an SMM. A single run consisted of five replicates of 10 initial short chains and five long final chains, and a static heating scheme with four temperatures (1.0, 1.3, 2.6, and 3.9). Initial chains were performed with 1,000 samples and a sampling interval of 20 (20,000 steps), with 1,000 trees recorded per short sample. The final five chains were carried out with 5,000 samples, a sampling interval of 20 (200,000 steps), and a burn-in period of 10,000 and 10,000 trees recorded per long chain. The confidence interval for $\theta$ and migration parameter $M$ was calculated using a percentile approach. 
We also tested whether the reconstructed historical migration rates followed an isolation-by-distance model. A regression analysis was performed using the number of migrants exchanged between pairs of populations and the natural logarithm of geographic distances (kilometers) between populations (either as donors or recipients of historical gene flow) (46).

\section{RESULTS}

Microsatellite information content and gene and genotype diversity. All of the loci were polymorphic (e-Xtra) in all populations except for TC05 (monomorphic in the ZU population) and $\mathrm{TC} 12$, which was monomorphic in four populations (BJ, TC, ZU, and QI). Allele frequencies at each locus were not evenly distributed. Either one of the alleles was observed with frequencies $>60 \%$ or two alleles were observed with frequencies $>30 \%$ (e-Xtra). Whereas 1 to 3 private alleles were found in $\mathrm{BJ}$, $\mathrm{GX}, \mathrm{WW}, \mathrm{JX}$, and HN, 16 private alleles were found in the riceinfecting population from Pattambi, India.

In total, 300 different genotypes were detected among the nine rice-infecting populations from China and the one from India (Table 1). In all, 21 genotypes were shared between at least two field populations from China and 4 of these were shared among three populations. The same genotypes were found in populations separated by more than $1,000 \mathrm{~km}$ (such as between $\mathrm{BJ}$ and $\mathrm{TC}$ or $\mathrm{BJ}$ and $\mathrm{WW}$ ). No genotypes were shared between the two most distant populations in China (BJ and GX) and none was shared between any of the populations from China and India.

Intermediate to high clonal fractions were observed for all populations, except for $\mathrm{HN}$, which had the lowest clonal fraction $(=0.16)$, the highest genotypic diversity $(=48.2)$, and evenly distributed genotypes (evenness $=0.74$ ) $($ Table 1$)$. HN also had the highest number of site-specific genotypes. Otherwise, clonality ranged from 0.29 in JX to 0.92 in ZU, which had only four genotypes. Populations located along the Yangtze River tributary region (central-eastern China) and the one from Guangxi province (GX) possessed the highest clonal fractions, as well as the lowest genotypic diversity and evenness (except for QI that had evenly distributed genotypes) (Table 1). After clone correction, the rice-infecting population from $\mathrm{ZU}$ was removed from further analysis due to its extreme clonality; thus, the number of populations analyzed further dropped from 10 to 9 .

The majority of the genotypes $(99 \%)$ were heterozygous for at least one locus. The expected heterozygosity $\left(\mathrm{H}_{\mathrm{E}}=\right.$ Nei's unbiased gene diversity) was 0.27 to 0.55 among the eight rice-infecting populations from China and the one from India. Nevertheless, Nei's gene diversity values were not significantly different, except for the BJ population that had the lowest gene diversity $(P \leq$ $0.05)$.

The overall allelic richness across populations was 4.1 (Table 1). The rice-infecting population from India had the highest value (5.0), significantly higher than six populations (BJ, GX, TC, WU, QI, and JX) $(P \leq 0.05)$, but similar to WW (4.4) and HN (4.1). BJ had the lowest allelic richness (3.5).

Population differentiation. Based on AMOVA estimates, the variation among populations represented $42.5 \%$ of the total variance. Pairwise analysis of population differentiation indicated that the populations located along the Yangtze River tributary region (TC, WW, WU, and QI) were not differentiated $\left(\Phi_{\mathrm{ST}}\right.$ values were not significantly different from zero) (Table 2). The populations from BJ, WW, WU, and QI also were not differentiated. Intermediate values of population differentiation $\left(\Phi_{\mathrm{ST}}\right.$ values of 0.08 to 0.37 , all significantly different from zero) were found in the comparisons between pairs of populations from northern China (BJ) and the ones from southern China (GX, HN, and JX). The highest level of subdivision was observed when comparing any population from China with the allopatric population from India $\left(\Phi_{\mathrm{ST}}\right.$ values of 0.64 to 0.74 , all significantly different from zero).

We found evidence of isolation by distance when comparing pairwise genetic distances $\left(\mathrm{F}_{\mathrm{ST}}\right.$ or $\left.\Phi_{\mathrm{ST}}\right)$ and geographical distances (Fig. 1). The regression was significant using either $\mathrm{F}_{\mathrm{ST}}\left(R^{2}=\right.$ $0.65 ; P<0.05)$ or $\Phi_{\mathrm{ST}}\left(R^{2}=0.61 ; P<0.05\right)$ as genetic distance measures (Fig. 1).

Test for admixture or hidden population structure. Overall, 9\% admixture was detected in the overall sample, corresponding to 26 genotypes that could be assigned to more than one cluster or to a cluster distinct from the one corresponding to its reference population (e-Xtra). However, the amount of admixture varied considerably among populations. No admixed genotypes were found in BJ, JX, HN, and Pattambi, India. On the other hand, the

TABLE 1. Measures of genotypic diversity in rice-infecting populations of Rhizoctonia solani AG-1 IA from China and one allopatric population from India

\begin{tabular}{|c|c|c|c|c|c|c|c|c|c|c|}
\hline Region & Population $^{\mathrm{r}}$ & $\begin{array}{l}\text { Sample } \\
\text { size }\end{array}$ & $\begin{array}{c}\text { Number of } \\
\text { genotypes }\end{array}$ & $\begin{array}{l}\text { Site-specific } \\
\text { genotypes } \\
(\mathrm{G})^{\mathrm{s}}\end{array}$ & $\begin{array}{l}\text { Clonal } \\
\text { fraction }\end{array}$ & $\begin{array}{l}\text { Stoddart and } \\
\text { Taylor's geno- } \\
\text { typic diversity }{ }^{t, u}\end{array}$ & Evenness $^{v}$ & $\mathrm{HE}^{\mathrm{w}, \mathrm{x}}$ & $\begin{array}{c}\text { Allelic } \\
\text { richness }^{\mathrm{x}, \mathrm{y}}\end{array}$ & $\begin{array}{l}\text { Number } \\
\text { of private } \\
\text { alleles }^{\mathrm{z}}\end{array}$ \\
\hline \multicolumn{11}{|l|}{ China } \\
\hline Northern & $\mathrm{BJ}$ & 48 & 31 & $25(6)$ & 0.35 & $22.59 \mathrm{a}$ & $0.73 \mathrm{ab}$ & $0.27 \mathrm{~b}$ & $3.40 \mathrm{c}$ & 1 \\
\hline \multirow[t]{4}{*}{ Eastern } & QI & 40 & 23 & $14(9)$ & 0.43 & $16.66 \mathrm{a}$ & $0.73 \mathrm{ab}$ & $0.45 \mathrm{ab}$ & $3.77 \mathrm{bc}$ & 0 \\
\hline & WW & 65 & 24 & $20(4)$ & 0.63 & $9.80 \mathrm{~b}$ & $0.41 \mathrm{c}$ & $0.42 \mathrm{ab}$ & $4.43 \mathrm{ab}$ & 2 \\
\hline & $\mathrm{TC}$ & 50 & 22 & $17(5)$ & 0.56 & $8.99 \mathrm{~b}$ & $0.41 \mathrm{c}$ & $0.43 \mathrm{ab}$ & $3.67 \mathrm{bc}$ & 0 \\
\hline & $\mathrm{ZU}$ & 49 & 4 & $3(1)$ & 0.92 & $2.02 \mathrm{c}$ & $0.50 \mathrm{~b}$ & ND & ND & 0 \\
\hline Central & WU & 51 & 23 & $20(3)$ & 0.55 & $9.67 \mathrm{~b}$ & $0.42 \mathrm{c}$ & $0.50 \mathrm{a}$ & $3.99 \mathrm{bc}$ & 0 \\
\hline \multirow[t]{3}{*}{ Southern } & GX & 69 & 28 & $23(5)$ & 0.59 & $10.99 \mathrm{~b}$ & $0.39 \mathrm{c}$ & $0.54 \mathrm{a}$ & $4.19 \mathrm{bc}$ & 2 \\
\hline & JX & 72 & 51 & $51(0)$ & 0.29 & $31.23 \mathrm{a}$ & $0.61 \mathrm{~b}$ & $0.49 \mathrm{a}$ & $4.09 \mathrm{bc}$ & 3 \\
\hline & $\mathrm{HN}$ & 77 & 65 & $65(0)$ & 0.16 & $48.20 \mathrm{a}$ & $0.74 \mathrm{a}$ & $0.55 \mathrm{a}$ & $4.21 \mathrm{abc}$ & 3 \\
\hline \multicolumn{11}{|l|}{ India } \\
\hline \multirow[t]{2}{*}{ Northern Kerala } & Pattambi & 51 & 29 & $29(0)$ & 0.43 & $11.46 \mathrm{ab}$ & $0.40 \mathrm{c}$ & $0.53 \mathrm{a}$ & $5.00 \mathrm{a}$ & 16 \\
\hline & Total & 572 & 300 & Overall = & 0.49 & 17.16 & 0.53 & 0.46 & 4.08 & 2.7 \\
\hline
\end{tabular}

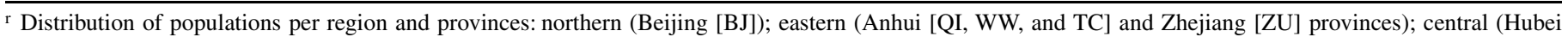
[WU] province); and southern (GuangXi [GX], JiangXi [JX], and Hunan [HN] provinces) China.

$s$ Numbers of genotypes shared with other populations are shown in parentheses.

t Stoddart and Taylor genotypic diversity $(49,50)$.

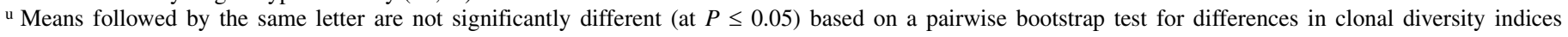
between populations calculated by GenoDive (36), based on 1,000 permutations with subsampling to match the size of the smallest population.

${ }^{v} G_{o}$ scaled by the maximum number of expected genotypes; evenness value $=1.0$ indicates that all genotypes have equal frequencies.

${ }^{w}$ Nei's unbiased gene diversity (39), also known as expected heterozygosity, averaged over all loci, corrected for the sample size.

x To test whether pairwise samples differed for Nei's unbiased gene diversity and allelic richness, we used FSTAT v.2.9.3.2 (18), based on 1,000 permutations.

y Calculated according to El Mousadik and Petit (13).

z Alleles occurring in only one population, calculated with Convert 1.31 (16). 
most admixed populations (GX, TC, WW, WU, and QI) had a proportion of admixed genotypes of 14 to $35 \%$.

From the total number of genotypes, 237 (80\%) were assigned to the populations from which they were originally sampled (probability of inclusion in the proper cluster $>0.90), 33(11 \%)$ genotypes were assigned with probabilities $<0.90$ (0.55 to 0.89 ), but none of those could be assigned to more than one cluster. The graphical representation of admixture is shown in the supplementary file.

HWE and GE tests. Results from HWE tests are given in Table 3. The rice-infecting population from BJ had most of the loci in HWE, except for the monomorphic locus (TC12). The WW and the Indian populations also had most of their loci at HWE. All other populations had at least three loci out of HWE. The HN and JX populations had more than half of their loci out of equilibrium. Most of the loci that were out of HWE showed a significant excess of homozygotes, consistent with inbreeding. Populations TC, WU, QI, JX, and HN had highly significant $\mathrm{F}_{\mathrm{IS}}$ values, also consistent with significant inbreeding in these populations (Table 3).

The rice-infecting population from Beijing was the only one in GE $\left(I_{A}=0.14 ; P=0.16\right.$, proportion of locus pairs at disequilibrium $=10.7 \%$ ). All the other populations had significant $I_{A}$ values that ranged from 0.27 in $\mathrm{HN}$ to 2.11 in TC (Table 3). Significant gametic disequilibrium of 11 to $42 \%$ of locus pairs in disequilibrium was found in all the other populations. After removing the admixed genotypes, the fraction of locus pairs in disequilibrium dropped in populations TC and WU (which had zero locus pairs in disequilibrium), WW, and GX. For these four populations, admixture was the cause of the previously observed gametic disequilibrium.

Demographic parameters and historical migration. Population sizes and historical migration rate estimates are presented in the supplementary file online. Values for $\theta$ ( 0.90 to 1.04$)$ were very similar among the rice-infecting populations from China. The highest estimate was from Pattambi, India, but it was not significantly different from the other populations $(\theta=1.18 ; 95 \%$ confidence interval $=1.03$ to 1.40 ).

Evidence for historical migration was found between all populations. In $56 \%$ of all pairwise inferences, more than one migrant per generation was exchanged among populations. High migration rates were indicated among populations located in the Yangtze River tributary region, including QI, WW, TC, and WU (e.g., $4 \mathrm{~N} m_{\mathrm{QI} \rightarrow \mathrm{TC}}=5.3,4 \mathrm{~N} m_{\mathrm{WW} \rightarrow \mathrm{WU}}=3.7,4 \mathrm{~N} m_{\mathrm{TC} \rightarrow \mathrm{WW}}=3.6$, and $4 \mathrm{~N} m_{\mathrm{WU} \rightarrow \mathrm{WW}}=3.4$ migrants per generation). In China, the population from $\mathrm{BJ}$ exchanged more than one migrant per generation with all the populations, except JX. The extent of migration was not always symmetrical between field populations. Of the 72 pairwise comparisons, 18 (25\%) had asymmetrical historical gene flow, indicated by nonoverlapping $95 \%$ confidence intervals around the estimate of $4 \mathrm{Nm}$ from or into each population. The highest asymmetrical rates were found for the comparisons involving either $\mathrm{QI}$ or $\mathrm{TC}$ populations $\left(4 \mathrm{~N} m_{\mathrm{QI} \rightarrow \mathrm{TC}}=5.3\right.$ and $4 \mathrm{~N} m_{\mathrm{TC} \rightarrow \mathrm{QI}}=2.7$ ). The lowest migration rates (average of $0.50 \pm$ 0.14 migrants exchanged) were found between the allopatric population from Pattambi (India) and all the others. The historical migration rates did not follow an isolation-by-distance model for most of the population pairs (Table 4; Fig. 2). Only BJ and HN fit

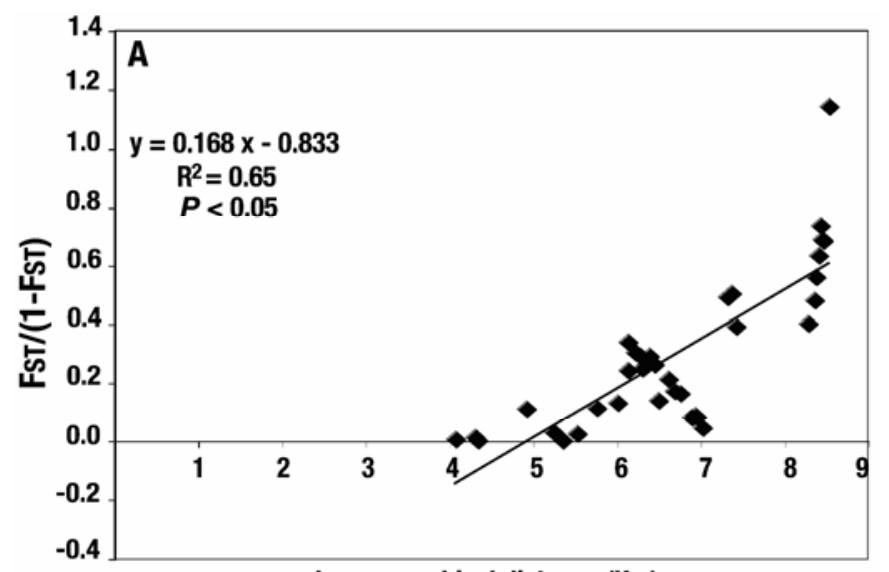

Ln geographical distance $(\mathrm{Km})$

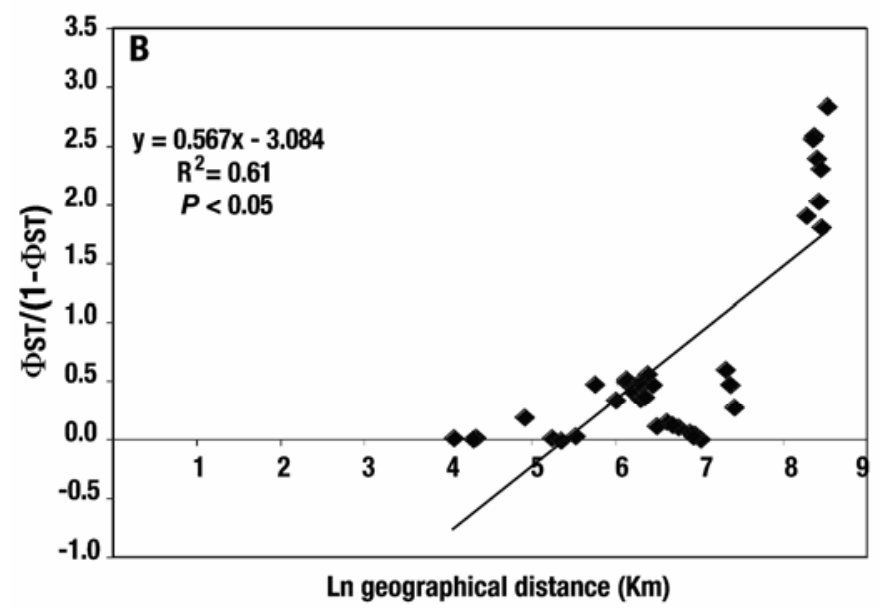

Fig. 1. Regression between genetic and geographical distance among pairs of populations of nine rice-infecting populations of Rhizoctonia solani AG-1 IA from China and one allopatric population from India. The estimation of differentiation is from Wright's $F_{\mathrm{ST}}$ or Slatkin's $\Phi_{\mathrm{ST}}$, an $\mathrm{F}_{\mathrm{ST}}$ analogue assuming a stepwise mutation model (3). Linear relationship between pairwise values of A, $\mathrm{F}_{\mathrm{ST}} /\left(1-\mathrm{F}_{\mathrm{ST}}\right)$ or $\mathbf{B}, \Phi_{\mathrm{ST}} /\left(1-\Phi_{\mathrm{ST}}\right)$ and the natural logarithm of geographic distances (kilometers) between all population pairs.

TABLE 2. Measures of differentiation among rice-infecting populations of Rhizoctonia solani AG-1 IA from China and one allopatric population from India based on $\mathrm{R}_{\mathrm{ST}}$ values ${ }^{\mathrm{Z}}$

\begin{tabular}{|c|c|c|c|c|c|c|c|c|c|}
\hline \multirow[b]{2}{*}{ Region } & \multirow[b]{2}{*}{ Populations } & \multicolumn{8}{|c|}{ Sum of squared size differences $\left(\Phi_{\mathrm{ST}}\right)$} \\
\hline & & $\mathrm{BJ}$ & QI & WW & $\mathrm{TC}$ & WU & GX & $\mathrm{JX}$ & $\mathrm{HN}$ \\
\hline \multicolumn{10}{|l|}{$\overline{\text { China }}$} \\
\hline Northern & BJ & - & & & & & & & \\
\hline & WW & $-0.002^{\mathrm{NS}}$ & $-0.003^{\mathrm{NS}}$ & _- & & & & & \\
\hline & $\mathrm{TC}$ & $0.052 * * *$ & $0.006^{\mathrm{NS}}$ & $0.012^{\mathrm{NS}}$ & - & & & & \\
\hline Central & WU & $0.036^{\mathrm{NS}}$ & $-0.014^{\mathrm{NS}}$ & $0.006^{\mathrm{NS}}$ & $0.024^{\mathrm{NS}}$ & - & & & \\
\hline \multicolumn{10}{|l|}{ India } \\
\hline Northern Kerala & Pattambi & $0.739 * * *$ & $0.698 * * *$ & $0.669^{* * *}$ & $0.644 * * *$ & $0.706^{* * *}$ & $0.655^{* * *}$ & $0.722 * * *$ & $0.719^{* * *}$ \\
\hline
\end{tabular}


the isolation-by-distance model, both as recipient (Fig. 2A2 and B2) and donor populations (Fig. 2A3 and B3). Two other populations (WU and JX, both from the Yangtze River tributary region) fit this model as recipient populations.

\section{DISCUSSION}

Understanding the complex population structure and dynamics of $R$. solani AG-1 IA requires differentiating the relative influences of life-history traits and historical processes in shaping present-day populations. $R$. solani AG-1 IA has the capacity for long-distance dispersal through human-mediated movement of sclerotia (22). The combination of a uniform agroecosystem and an efficient inoculum dispersal that enhances gene flow can act as a major homogenizing force that would decrease genetic differentiation and ultimately lead to panmixia. In the absence of gene flow, geographical isolation and local adaptation would promote isolation by distance and eventually lead to significant levels of genetic differentiation (21).

Here, we provide the first in-depth population genetic analysis of the rice-infecting sheath blight pathogen $R$. solani AG-1 IA from the center of origin of its host (4). Our null hypothesis was that the rice-infecting populations from China and India would not be differentiated. The alternative hypotheses were that differentiation would occur only at extreme geographical distances or would increase with geographical distance. The population genetic structure of $R$. solani AG-1 IA from nine different field populations from China and the allopatric population from India was consistent with gene flow following an isolation-by-distance model. Our findings suggested limited long-distance gene flow and high levels of gene flow among populations located in the Yangtze River tributary region.

One consequence of gene flow is population admixture (41). In fact, the four nondifferentiated populations along the Yangtze region (TC, WW, WU, and QI) had the highest levels of ad- mixture, with proportions of admixed genotypes of 17 to $34 \%$. Twenty-one MLMGs were shared amongst the Chinese riceinfecting populations situated along the Yangtze River tributary region. Using the allele frequencies at each locus, we calculated the probability of unrelated isolates sharing the same multilocus genotype (53). Because the probabilities were low (ranging up to $10^{-11}$ ), these genotypes were probably not shared by chance. Rather we propose that genotype flow may have been mediated through the dispersal of sclerotia in irrigation water within this region. Rice crops in China are generally flooded until 15 days before harvest, when the field is drained (54). Though separated by significant distances (58 to $250 \mathrm{~km}$ ), these four populations were all connected by small watercourses, which are tributaries of the Yangtze River. The continuous flow of the irrigation water system diverted from the river to individual fields and then drained back into the river network could facilitate the dispersal of floating sclerotia and, consequently, may have favored gene and genotype flow among these populations.

The three southern-most populations from China (GX, HN, and $\mathrm{JX}$ ) and the one from India were the most differentiated populations. Geographical isolation is the most likely cause of the strong genetic differentiation observed among these populations compared with the other populations from China. In contrast to the isolation with distance found for the southern populations, high current gene flow was indicated among the populations from the Yangtze River (TC, QI, WW, and WU) and the population from $\mathrm{BJ}$ which is, on average, $1,050 \mathrm{~km}$ away from that river network. We hypothesize that the high level of gene flow in this case could have been mediated by the long-distance movement of contaminated material, such as infested seed or straw, as already reported for the soybean-infecting $R$. solani AG-1 IA in Brazil (10)

In general, the historical migration rates detected among the Chinese rice-infecting populations of $R$. solani AG-1 IA were high. The average of the maximum migration rates observed was

TABLE 3. Tests for random association of alleles within each locus and between pairs of loci in rice-infecting populations of Rhizoctonia solani AG-1 IA from China and one allopatric population from India

\begin{tabular}{|c|c|c|c|c|c|c|c|c|c|}
\hline \multirow[b]{2}{*}{ Region } & \multirow[b]{2}{*}{ Populations $^{t}$} & \multirow[b]{2}{*}{ Admixed genotypes ${ }^{u}$} & \multirow[b]{2}{*}{$N$} & \multirow[b]{2}{*}{$\begin{array}{c}\text { Number of } \\
\text { loci under } \\
\text { HWE }^{\mathrm{v}}\end{array}$} & \multirow[b]{2}{*}{$F_{I S}{ }^{\mathrm{w}}$} & \multicolumn{4}{|c|}{ Gametic equilibrium estimates } \\
\hline & & & & & & $I_{A}^{\mathrm{x}}$ & $P$ value $^{y}$ & $\begin{array}{l}\text { Locus pairs at } \\
\text { significant } \\
\text { disequilibrium }^{z}\end{array}$ & $\%$ \\
\hline Northern & BJ & No admixture detected & 31 & $8 / 8^{*}$ & $0.082^{\mathrm{NS}}$ & 0.14 & 0.163 & 3 in 28 & 10.7 \\
\hline \multirow[t]{3}{*}{ Eastern } & QI & $4 / 23(=17.4 \%)$ & 23 & $5 / 8^{*}$ & $0.347 * * *$ & 0.60 & $<0.001$ & 3 in 28 & 10.7 \\
\hline & QI with no admixture & & 19 & $6 / 8^{*}$ & $0.351 * * *$ & 0.80 & $<0.001$ & 3 in 28 & 10.7 \\
\hline & TC with no admixture & & 17 & $8 / 8^{*}$ & $0.180^{\mathrm{NS}}$ & 0.63 & 0.01 & 0 in 28 & 0.0 \\
\hline \multirow[t]{2}{*}{ Central } & WU & $8 / 23(=34.8 \%)$ & 23 & $6 / 9$ & $0.289 * * *$ & 1.18 & $<0.001$ & 10 in 36 & 27.8 \\
\hline & WU with no admixture & & 15 & $6 / 8^{*}$ & $-0.045^{\mathrm{NS}}$ & 0.76 & $<0.001$ & 0 in 28 & 0.0 \\
\hline \multirow[t]{3}{*}{ Southern } & GX & $4 / 28(=14.3 \%)$ & 28 & $6 / 9$ & $-0.955^{\mathrm{NS}}$ & 1.10 & $<0.001$ & 7 in 36 & 19.4 \\
\hline & GX with no admixture & & 24 & $6 / 9$ & $-0.047^{\mathrm{NS}}$ & 1.09 & $<0.001$ & 5 in 36 & 13.9 \\
\hline & JX & No admixture detected & 51 & $4 / 9$ & $0.271^{* * * *}$ & 0.51 & $<0.001$ & 9 in 36 & 25.0 \\
\hline
\end{tabular}

${ }^{\mathrm{t}}$ Beijing (BJ); Anhui (QI, WW, and TC) and Zhejiang (ZU) provinces; Hubei (WU) province; and GuangXi (GX), JiangXi (JX), and Hunan (HN) provinces.

"Admixture determined using an assignment test implemented by the computer program STRUCTURE (41); light shading indicates populations from QI, WW, TC, WU, and GX after removal of admixed genotypes.

${ }^{v}$ Hardy Weinberg equilibrium (HWE) test performed according to an exact test analogous to the Fisher exact test, using a Markov chain with forecasted length of $100,000(20) ; *=$ one monomorphic locus.

${ }^{\text {w }}$ Population-specific inbreeding coefficient $\left(F_{I S}\right)$ indices and $P$ values calculated based on 1,023 permutations using ARLEQUIN 3.2 (14).

${ }^{\mathrm{x}} I_{A}$ is an index of multilocus gametic disequilibrium (31).

${ }^{\mathrm{y}}$ Testing $H_{O}=$ complete panmixia based on 1,000 randomizations; for diploid data, the two alleles at a locus are shuffled together (associations between alleles at a locus are maintained in the randomized data sets); thus, the test is purely for associations between loci (1)

${ }^{\mathrm{z}}$ Pairs of loci at significant disequilibrium according to the Fisher exact test (probability test) using a Markov chain with 1,000 batches and 1,000 iterations/batch, implemented by GenePop 3.4 (42), after Bonferroni correction for multiple comparisons (44). 
$3.17 \pm 1.04$ migrants/generation. Lower historical migration rates were detected amongst other $R$. solani AG-1 IA populations from around the world, such as the soybean-infecting populations from different Brazilian states (maximum $4 \mathrm{Nm}=1.71$ ) (10) and the rice-infecting populations from Louisiana and Texas (maximum $4 \mathrm{~N} m=1.52)(6)$.

The estimated historical migration rates did not always follow the isolation-by-distance model. High historical migration rates (4Nm ranging from a minimum of 1.1 up to a maximum of 5.3 migrants/generation) were found among populations from the Yangtze tributary region (TC, QI, WW, and WU). A migration rate close to one is considered the minimum amount needed to prevent populations from diverging due to genetic drift (21). The lowest migration rates were found between the rice-infecting population from India and all the other populations from China, either as donor or recipient populations. High historical migration was inferred among the three most Southern populations from China (GX, HN, and JX) and all other Chinese populations $(4 \mathrm{Nm}=1.0$ to 3.7$)$. To explain this finding, we hypothesize that the three southern populations had greater genetic exchange with other Chinese populations in the past (perhaps due to shared infested seed or trade of other goods contaminated with sclerotia) compared with the limited genetic exchange that occurs in contemporary populations.

Our last question was related to the reproductive mode of riceinfecting populations of $R$. solani AG-1 IA from China. $R$. solani
AG-1 IA was thought to be mainly an asexual fungus on rice, though sexual structures from its teleomorph (T. cucumeris) have been commonly observed in rice fields (23). Population genetic evidence from four studies of rice-infecting populations of $R$. solani AG-1 IA in India, South America (Venezuela), and the United States (Texas and Louisiana) have challenged this view of an asexual fungus. The results in these studies were consistent with a reproductive mode varying from strictly recombining (with predominantly sexual reproduction) to a mixed reproductive system (which included recombination events followed by clonal expansion during the growing season) $(6,17,25,45)$. Our expectation was that the rice-infecting $R$. solani AG-1 IA would be sexually recombining in China. Sexually recombining organisms are expected to have high genotypic diversity, low clonality, and neutral markers at HWE proportions and GE $(35,38)$.

Most of the rice-infecting populations from China had intermediate to high genotypic diversity and low clonal fractions (Table 1). Further evidence of recombination was based on the exact test of HWE (15). The rice-infecting populations BJ and WW had most of the loci under HWE expected proportions (consistent with sexual production), suggesting that basidiospores may play an important role in disease epidemiology. The population from Pattambi, India (formerly genotyped using RFLPs) (25), which was included as an outside comparison, also had most of the loci under HWE, supporting previous findings of a recombining population structure in India (25). Evidence for re-

TABLE 4. Summary of historical migration patterns between pairs of rice-infecting populations of Rhizoctonia solani AG-1 IA from China and one allopatric population from India

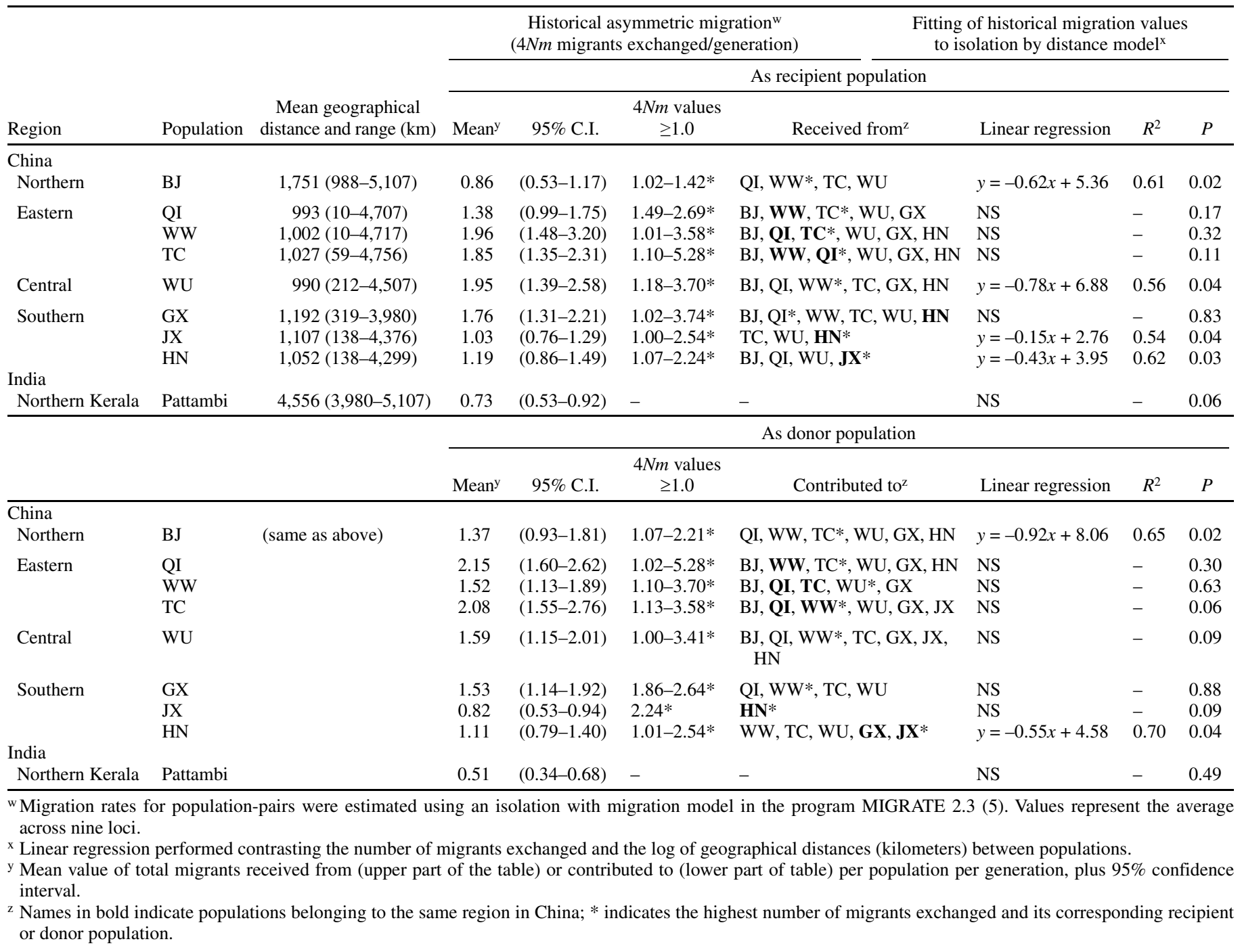


combination was also found in GX, TC, WU, and QI, where more than half of the loci conformed to HWE expectations. Gametic disequilibrium varied from intermediate to high for most of the populations, with the exception of BJ. Gametic disequilibrium can be caused by several factors, including linkage, population admixture, genetic drift, nonrandom mating, population expansion, and selection $(21,38)$.

We further investigated the two most probable causes for the observed GD: population admixture and nonrandom mating. After removing admixed genotypes, GD fell in populations from WW,
TC, WU, and GX (as measured by $I_{A}$ or the proportion of locus pairs in GD). The proportion of loci under HWE expectations also increased for three of these populations: WW, TC, and WU (Table 3 ) and $F_{I S}$ was no longer significant for TC and WU populations. Our interpretation was that admixture had contributed to but was not the sole explanation for the observed disequilibrium. The other plausible cause of GD was inbreeding (assortative mating). Significant and positive $\mathrm{F}_{\mathrm{IS}}$ values were found for QI, JX, and $\mathrm{HN}$, which suggested that these populations exhibited a significant degree of inbreeding within the sexual component of the
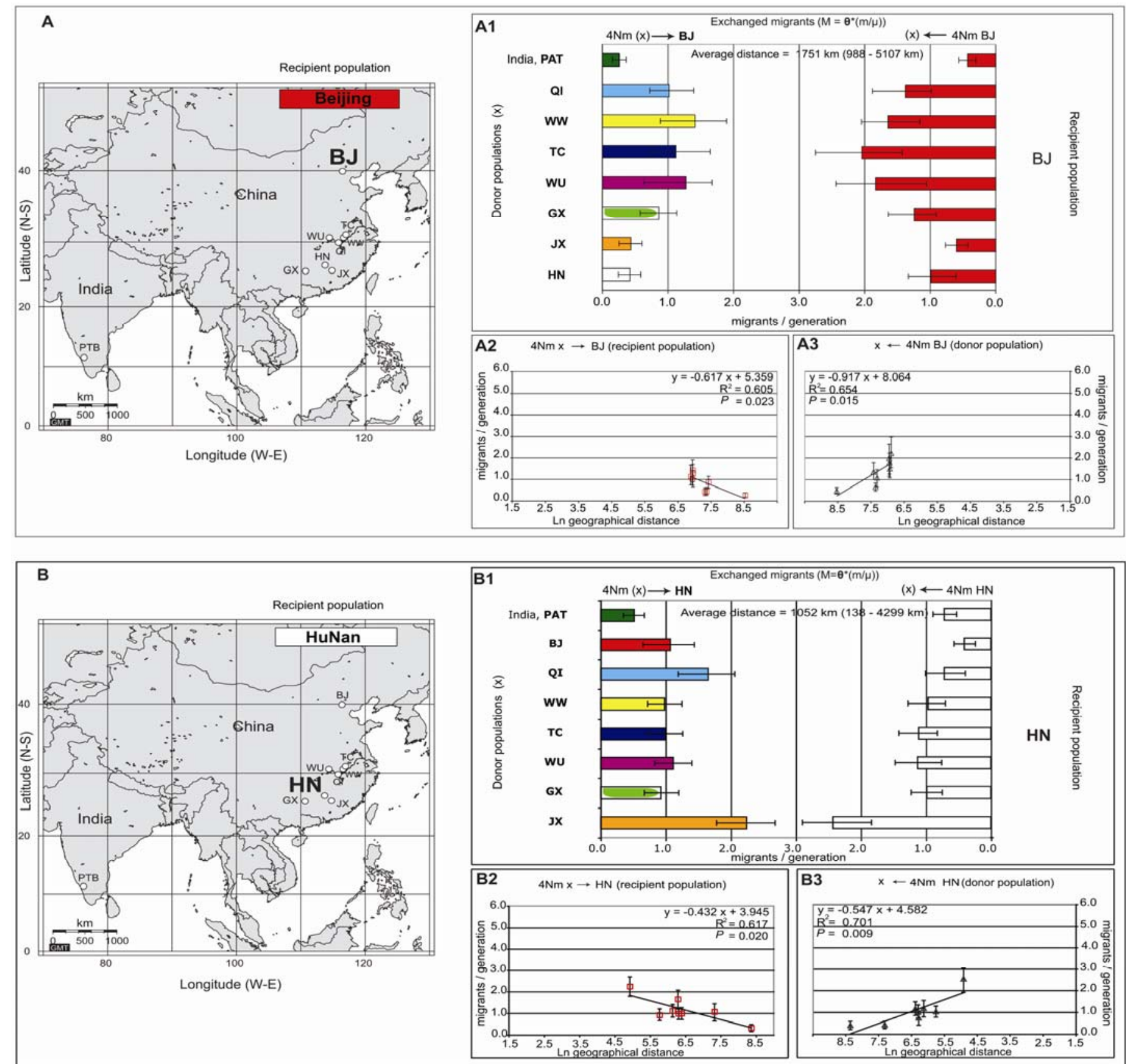

Fig. 2. A and B, Estimates of demographic parameters from the divergence among rice-infecting populations of Rhizoctonia solani AG-1 IA from China and one allopatric population from India, based on variation in nine microsatellite loci. Migration between geographical populations was estimated using an isolation with migration model. Inferred historical migration rates $(\mathrm{M}=$ migrants/generation) were estimated using the program MIGRATE 2.3 [60]. Two populations were chosen to illustrate the historical exchange of migrants: A, Beijing (BJ) and B, HuNan (HN). Colored bars indicate the inferred asymmetrical historical migration between source and recipient populations. For example, in A1, red bars on the right indicate inferred migration from the rice-infecting population from BJ, while colored bars on the left indicate inferred migration from the other Chinese and Indian rice-infecting populations toward BJ. In B1, white bars on the right indicate inferred migration from HN while colored bars indicate inferred migration from all the other source populations toward HN. Bars indicate estimates of inferred migration rates with $95 \%$ confidence intervals. A2, A3, B2, and B3, Regression between historical migration rates and geographical distance among pairs of populations of nine rice-infecting populations of $R$. solani AG-1 IA. The historical migration rates followed an isolation-by-distance model for both BJ (A2 and $\mathrm{A} 3$ ) and $\mathrm{HN}$ (B2 and B3), either as donor or recipient populations. 
reproduction. Inbreeding does not necessarily reflect a homothallic mating system but it could be a hint of homothallism in $R$. solani AG-1 IA.

Taking all of these results together, we propose a recombining reproductive mode for the Chinese rice-infecting populations $\mathrm{BJ}$, $\mathrm{WW}, \mathrm{TC}$, and WU and a mixed reproductive mode for QI and GX, which includes recombination events followed by clonal expansion during the growing season. We did not find strong evidence for sexual reproduction in the ZU populations, which was mainly clonal (clonal fraction $=92 \%$ ), yielding only four distinct genotypes after clone correction. We propose that the mode of reproduction of this population was mainly asexual. In summary, the balance between asexual and sexual reproduction for the Chinese rice-infecting populations of $R$. solani AG-1 IA was population dependent. However, questions about the frequency of occurrence and the factors limiting recombination remain unanswered until further evidence is gathered (e.g., the presence and ratios of alleles at mating type loci in these populations). An unbalanced mating type ratio could explain, for instance, why the ZU population had no evidence for recombination. Unfortunately, the mating system of $R$. solani AG-1 IA remains unknown and mating type loci have not yet been identified.

The final observation from our study concerns the risk category associated with the evolutionary potential of the rice-infecting $R$. solani AG-1 IA. In the Chinese populations, we found high genetic diversity, high gene flow, some genotype flow, and evidence of a mixed reproductive system. According to the risk model framework proposed by McDonald and Linde $(34,35)$, these characteristics place $R$. solani AG-1 IA among pathogens with the highest evolutionary potential. Under this scenario, control measures such as fungicide applications or deployment of major resistance genes should be implemented with caution and measures to minimize gene flow, such as reducing the spread of sclerotia via shared irrigation systems or contaminated machinery, are strongly recommended.

\section{ACKNOWLEDGMENTS}

J. Bernardes-de-Assis and M. Storari contributed equally to this research. This work was partially funded by an ETH grant (TH-16/06-1) to P. C. Ceresini. The SSR data was collected using the facilities of the Genetic Diversity Center at the ETH. The statistical analysis on migration patterns were carried out using the Computational Biology Service Unit from Cornell University, which is partially funded by Microsoft Corporation.

\section{LITERATURE CITED}

1. Agapow, P.-M., and Burt, A. 2001. Indices of multilocus linkage disequilibrium. Mol. Ecol. Notes 1:101-102.

2. Amos, W., Hoffman, J. I., Frodsham, A., Zhang, L., Best, S., and Hill, A. V. S. 2007. Automated binning of microsatellite alleles: problems and solutions. Mol. Ecol. Notes 7:10-14.

3. Balloux, F., and Lugon-Moulin, N. 2002. The estimation of population differentiation with microsatellite markers. Mol. Ecol. 11:155-165.

4. Balter, M. 2007. Plant science: seeking agriculture's ancient roots. Science 316:1830-1835

5. Beerli, P., and Felsenstein, J. 2001. Maximum likelihood estimation of a migration matrix and effective population sizes in $\mathrm{n}$ subpopulations by using a coalescent approach. PNAS 98:4563-4568.

6. Bernardes-de-Assis, J., Peyer, P., Zala, M., Rush, M., McDonald, B. A., and Ceresini, P. C. 2008. Divergence between sympatric rice- and soybean-infecting populations of Rhizoctonia solani AG-1 IA. Phytopathology 98:1326-1333.

7. Brown, A. H. D., Feldman, M. W., and Nevo, E. 1980. Multilocus structure of natural populations of Hordeum spontaneum. Genetics 96:523-536.

8. Carling, D. E., Kuninaga, S., and Brainard, K. A. 2002. Hyphal anastomosis reactions, rDNA-internal transcribed spacer sequences, and virulence levels among subsets of Rhizoctonia solani anastomosis group-2 (AG-2) and AG-BI. Phytopathology 92:43-50.
9. Ciampi, M. B., Kuramae, E. E., Fenille, R. C., Meyer, M. C., Souza, N. L., and Ceresini, P. C. 2005. Intraspecific evolution of Rhizoctonia solani AG-1 IA associated with soybean and rice in Brazil based on polymorphisms at the ITS-5.8S rDNA operon. Eur. J. Plant Pathol. 113:183-196.

10. Ciampi, M. B., Meyer, M. C., Costa, M. J. N., Zala, M., McDonald, B. A., and Ceresini, P. C. 2008. Genetic structure of populations of Rhizoctonia solani anastomosis group-1 IA from soybean in Brazil. Phytopathology 98:932-941.

11. Cubeta, M. A., and Vilgalys, R. 1997. Population biology of the Rhizoctonia solani complex. Phytopathology 87:480-484.

12. Defeng, Z., and Shaokai, M. 1995. Rice production in China under current and future climates. Page 217-235 in: Modeling the impact of climate change on rice production in Asia. R. B. Matthews, M. J. Kropff, D. Bachelet, and H. H. v. Laar, eds. CAB International, Wallingford, UK and International Rice Research Institute, Manila, Philippines.

13. El Mousadik, A., and Petit, R. J. 1996. High level of genetic differentiation for allelic richness among populations of the argan tree (Argania spinosa (L.) Skeels) endemic to Morocco. Theor. Appl. Genet. 92:832-839.

14. Excoffier, L., Laval, G., and Schneider, S. 2005. Arlequin (version 3.0): an integrated software package for population genetics data analysis. Evol. Bioinform. Online 1:47-50.

15. Falconer, D. S., and Mackay, T. F. C. 1996. Introduction to Quantitative Genetics, 4th ed. Essex: Longmans Green, Harlow.

16. Glaubitz, J. C. 2004. Convert: A user-friendly program to reformat diploid genotypic data for commonly used population genetic software packages. Mol. Ecol. Notes 4:309-310.

17. González-Vera, A. D., Bernardes-de-Assis, J., Ciampi, M. B., Zala, M., McDonald, B. A., and Ceresini, P. C. 2008. Population genetics of the rice- and maize-infecting pathogen Rhizoctonia solani AG 1 IA from Venezuela. Page 51 in: Abstr. 4th Int. Symp. Rhizoctonia. Humboldt Universitaet, Berlin.

18. Goudet, J. 1995. FSTAT (version 1.2): a computer program to calculate Fstatistics J. Hered. 86:485-486.

19. Grunwald, N. J., Goodwin, S. B., Milgroom, M. G., and Fry, W. E. 2003. Analysis of genotypic diversity data for populations of microorganisms. Phytopathology 93:738-746.

20. Guo, S. W., and Thompson, E. A. 1992. Performing the exact test of Hardy-Weinberg proportions for multiple alleles. Biometrics 48:361-372.

21. Hartl, D. L., and Clark, A. G. 1997. Principles of Population Genetics, 3rd ed. Sinauer Associates, Sunderland, MA.

22. Inagaki, K. 1998. Dispersal of rice sheath blight fungus, Rhizoctonia solani AG-1(IA), and subsequent disease development in paddy fields, from survey of vegetative compatibility groups. Mycoscience 39:391-397.

23. Jones, R. K., and Belmar, S. B. 1989. Characterization and pathogenicity of Rhizoctonia spp. isolated from rice, soybean, and other crops grown in rotation with rice in Texas. Plant Dis. 73:1004-1010.

24. Lee, F. N., and Rush, M. C. 1983. Rice sheath blight: a major rice disease. Plant Dis. 67:829-832

25. Linde, C. C., Zala, M., Paulraj, R. S. D., McDonald, B. A., and Gnanamanickam, S. S. 2005. Population structure of the rice sheath blight pathogen Rhizoctonia solani AG-1 IA from India. Eur. J. Plant Pathol. 112:113-121.

26. Manly, B. F. J. 1991. Randomization, Bootstrap and Monte Carlo Methods in Biology, 2nd ed. Chapman \& Hall and CRC, London.

27. Mantel, N. A. 1967. The detection of disease clustering and a generalized regression approach. Cancer Res. 27:209.

28. Marchetti, M. A., and Bollich, C. N. 1991. Quantification of the relationship between sheath blight severity and yield loss in rice. Plant Dis. 75:773-775.

29. Matsumoto, M. 2002. Trials of direct detection and identification of Rhizoctonia solani AG 1 and AG 2 subgroups using specifically primed PCR analysis. Mycoscience 43:185-189.

30. Matsumoto, T., Yamamoto, W., and Hirane, S. 1932. Physiology and parasitology of the fungi generally referred to as Hypochnus sasakii Shirai. I. Differentiation of the strains by means of hyphal fusion and culture in differential media. Jpn. J. Trop. Agric. 4:370-388.

31. Maynard Smith, J., Smith, N. H., O'Rourke, M., and Spratt, B. G. 1993. How clonal are bacteria? PNAS 90:4384-4388.

32. McDermott, J. M., and McDonald, B. A. 1993. Gene flow in plant pathosystems. Annu. Rev. Phytopathol. 31:353.

33. McDonald, B. A. 1997. The population genetics of fungi: tools and techniques. Phytopathology 87:448-453.

34. McDonald, B. A., and Linde, C. 2002. The population genetics of plant pathogens and breeding strategies for durable resistance. Euphytica 124:163-180.

35. McDonald, B. A., and Linde, C. 2002. Pathogen population genetics, evolutionary potential, and durable resistance. Annu. Rev. Phytopathol. 40:349-379. 
36. Meirmans, P. G., and Van Tienderen, P. H. 2004. GenoType and GenoDive: two programs for the analysis of genetic diversity of asexual organisms. Mol. Ecol. Notes 4:792-794.

37. Meyer, M. C., and Yorinori, J. T. 1999. Incidência de doenças da soja em regiões tropicais. Page 457 in: Abstr. Congresso Brasileiro de Soja. Embrapa-Soja, Londrina, PR, Brazil.

38. Milgroom, M. G. 1996. Recombination and the multilocus structure of fungal populations. Annu. Rev. Phytopathol. 34:457-477.

39. Nei, M. 1978. Estimation of average heterozygosity and genetic distance from a number of individuals. Genetics 89:538-590.

40. Ou, S. H. 1985. Rice Diseases. Commonwealth Agricultural Bureaux, Farnham Royal.

41. Pritchard, J. K., Stephens, M., and Donnelly, P. 2000. Inference of population structure using multilocus genotype data. Genetics 155:945959.

42. Raymond, M., and Rousset, F. 1995. GENEPOP (version 1.2): population genetics software for exact tests and ecumenicism. J. Hered. 86:248-249.

43. Ren, C. M., Gao, B. D., and He, Y. C. 2001. Advance in rice resistance to rice sheath blight. Plant Prot. 27:32-36. (In Chinese with English abstract)

44. Rice, W. R. 1989. Analyzing tables of statistical tests. Evolution 43:223225.

45. Rosewich, U. L., Pettway, R. E., McDonald, B. A., and Kistler, H. C. 1999. High levels of gene flow and heterozygote excess characterize Rhizoctonia solani AG-1 IA (Thanatephorus cucumeris) from Texas. Fungal Genet. Biol. 28:148-159.

46. Rousset, F. 1997. Genetic differentiation and estimation of gene flow from $F$ statistics under isolation by distance. Genetics 145:1219-1228.

47. Slatkin, M. 1995. A measure of population subdivision based on microsatellite allele frequencies. Genetics 139:457-462.

48. Sneh, B., Burpee, L., and Ogoshi, A. 1991. Identification of Rhizoctonia Species. The American Phytopathological Society, St. Paul, MN.

49. Stoddart, J. A. 1983. A genotypic diversity measure. J. Hered. 74:489-490.

50. Stoddart, J. A., and Taylor, J. F. 1988. Genotype diversity: estimation and prediction in samples. Genetics 118:705-711.

51. Stukenbrock, E. H., and McDonald, B. A. 2008. The origins of plant pathogens in agro-ecosystems. Annu. Rev. Phytopathol. 46:75-100.

52. Tu, C. C., Chang, Y. C., and Wang, C. W. 1979. Studies on ecology of Rhizoctonia solani, the causal organism of sheath blight of rice. Natl. Sci. Counc. Month. Republic China 7:1208-1219. (In Chinese with English abstract)

53. Weir, B. S. 1996. Genetic Data Analysis. 2nd ed. Sinauer Associates, Sunderland, MA.

54. Willocquet, L., Fernandez, L., and Savary, S. 2000. Effect of various crop establishment methods practised by Asian farmers on epidemics of rice sheath blight caused by Rhizoctonia solani. Plant Pathol. 49:346-354.

55. Wright, S. 1965. The interpretation of population structure by $F$ statistics with special regard to systems of mating. Evolution 19:395-420.

56. Zala, M., McDonald, B. A., Bernardes de Assis, J., Ciampi, M. B., Storari, M., Peyer, P., and Ceresini, P. C. 2008. Highly polymorphic microsatellite loci in the maize- and rice-infecting fungal pathogen Rhizoctonia solani anastomosis group 1 IA. Mol. Ecol. Resour. 8:686689.

57. Zhan, J., Pettway, R. E., and McDonald, B. A. 2003. The global genetic structure of the wheat pathogen Mycosphaerella graminicola is characterized by high nuclear diversity, low mitochondrial diversity, regular recombination, and gene flow. Fungal Genet. Biol. 38:286-297. 